\title{
10. Innovation, measurement and policy
}

\subsection{INTRODUCTION}

For almost 30 years, official statistics on innovation have come from business surveys. Innovation was seen as a business phenomenon, and the source of jobs and growth. Now consider innovation in all sectors and the interaction of units in all sectors as they engage in innovation. As an example, the results can demonstrate the influence of government innovation on business innovation.

In Chapter 6, the general definition of innovation was introduced, applicable in all economic sectors of the System of National Accounts. The sectors were defined in Chapter 7 where sector-specific innovation was discussed. Chapter 8 dealt with innovation that can appear in any sector, such as innovation in the informal economy. This chapter examines statistical measurement of innovation in any sector and then goes on to discuss innovation policy in this context. The key point is that a general definition of innovation, while fundamental, is just the beginning in understanding measurement and policy in any or all economic sectors.

To start with, the innovation of the institutional unit in each sector can be identified by a survey. The surveys can be business surveys for the business sector or business-like surveys in the case of the non-profit organisation serving households (NPISH) sector and the general government sector (or the public sector). Social surveys, dealing with people, are required to measure innovation in the household sector. This is discussed in Section 10.2.

Another measurement issue is the digital economy and how it affects the measurement of innovation and the collection of data. The rapid development of the digital economy, and its implication for statistical measurement is a factor discussed in Section 10.3. 
Section 10.4 considers how to use a systems approach to bring together the measurement of innovation in all economic sectors, starting with agreement on how to use the general definition of innovation and how to measure innovation in each sector.

The remaining sections, $10.5-10.8$, deal with innovation policy and Section 10.9 concludes.

\subsection{INNOVATION AND DATA COLLECTION}

For innovation in the business sector, the use of surveys is well covered by the Oslo Manual (OECD/Eurostat 2018) which stresses the importance of a current business register. Business registers are well established in developed countries, but this is not always the case in developing countries. In any country, the business register, maintained by the national statistical office (NSO), may not be available to researchers from outside the statistical office, resulting in the use of commercial registers which might not be as comprehensive or as up to date as the NSO register.

Business registers, and how they capture new firms and detect and remove firms that are no longer trading, is an ongoing activity. The international forum dealing with this subject is the Wiesbaden Group on

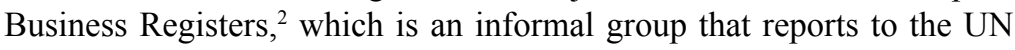
Statistical Commission.

When drawing a sample from a business register, a decision is made about the degree of detail that is required for the purpose of the survey. Every entry in the business register should have an industrial classification. An example of such a classification is provided by the International Standard Industrial Classification (ISIC) (UN Statistics Division 2008). ISIC, Revision 4 is divided into sections (one letter of the alphabet), divisions (two digits), groups (three digits) and classes (four digits). If the survey is to report on 'groups', the three-digit level, the sample has to be drawn at the group level with sufficient units to provide population estimates for the groups being studied.

One of the challenges of the digital economy is that units change their activities rapidly while the current version of ISIC, Revision 4 was approved 14 years ago in 2006. The question is whether ISIC, Revision 4 can provide a meaningful classification for studying innovation in all sectors of the economy in 2020. Of course, this question applies to all industrial classifications, not just ISIC. 
Table 10.1 Business characteristics and innovation

\begin{tabular}{lll}
\hline & High entry rate & Low entry rate \\
\hline High exit rate & Volatile & Structural change \\
& New industries & UK retail sector and pubs \\
\multirow{3}{*}{ Low exit rate } & New opportunities & Stable \\
& Disruptive innovation & Audit and actuarial services, ... \\
\hline
\end{tabular}

Source: The author.

Another issue is where in the firm the survey should be placed. Should it be at the firm level or the establishment level (or kind-of-activity unit level (KAU))?

For a business register that manages entry and exit well, Table 10.1 could be used to place all $\mathrm{N}$ units in the register, classified at the desired level of ISIC, into one of the quadrants. This requires a decision on what is a high level of entry in year Y, and of exit in year Y-1, using the following equation. Once a decision is made on high and low exit and entry, the units could be classified using ISIC codes and then the presence of innovation probed using surveys, or other means of acquiring data.

$$
\mathrm{N}_{\mathrm{Y}} / \mathrm{N}_{\mathrm{Y}-1}=1+\left(\mathrm{N}_{\text {EnteredY }}-\mathrm{N}_{\text {ExitedY-1 }}\right) / \mathrm{N}_{\mathrm{Y}-1}
$$

Business surveys, or business-like surveys, could then be used to find innovation in the business sector, the NPISH sector and in the public sector (general government sector combined with the aggregate of public corporations (EC et al. 2009: para. 22.41)). For the household sector, social surveys are required and there is also a question about how to draw a sample that represents the population being studied.

Registers of institutional units and of the population are needed for surveys, but there is growing interest in ways of gathering data that do not require a survey. The National Research Council (2014) provides a discussion, and recommendations, on how innovation is measured and how it could be measured, as does the National Academies of Sciences, Engineering and Medicine (2017). These reports come from a panel and a workshop commissioned by the National Center for Science and Engineering Statistics (NCSES) which is part of the National Science Foundation (NSF) in the US and is a statistical office. The reports provide insight into alternative ways of gathering data and ways of providing information on innovation. The key observation is that data collection 
is expected to change over the next decade and the digital economy is a driving force in this change.

\subsection{DIGITAL ECONOMY}

The digital economy is a relatively new phenomenon and it has implications for both innovation measurement and innovation policy. At the OECD, the project 'Going Digital: Making the Transformation Work for Growth and Wellbeing' has produced many studies of the digital economy. From the measurement perspective, the key publication is OECD (2019a), which deals with measuring the digital transformation. It makes a call to action because of the speed with which the subject is developing and the need to act now to produce relevant indicators and measurement tools.

Four actions are proposed to produce data that can be used for indicators (OECD 2019a: 17). The actions are to:

1. make the digital transformation visible in economic statistics

2. understand the economic impacts of digital transformation

3. measure wellbeing in the digital age, and

4. design new approaches to data collection.

Five additional actions focus on specific areas. The actions are to:

1. monitor transformative technologies (notably the Internet of Things, AI and Blockchain)

2. make sense of data and data flows

3. define and measure skills needed in the digital era

4. measure trust in online environments, and

5. assess governments' digital strengths.

Action 1, the making of digital transformation visible in economic statistics, echoes the earlier discussion about the need to have innovation, measured in all economic sectors, present in official statistics, which include economic statistics. While Chapter 5 of OECD (2019a) deals with 'Unleashing Innovation', it is more focused on preparing the way for innovation than on the activity of innovation. The first task is to understand the digital economy, and once that has been accomplished, in whatever sector, the question can be raised about measuring innovation.

The International Monetary Fund (IMF 2018) also addresses measuring the digital economy and is reluctant to change the conceptual frame- 
work of GDP to include 'free digital services', but it does recommend that 'indicators of welfare' from free digital products can, and should, be developed in the context of non-market production outside of the boundary of the GDP. The IMF goes on to suggest that 'recommendations for overcoming the measurement challenges posed by digitalisation include improving access by national statistics compilers specifically to administrative data and generally "Big Data". Free digital services were discussed in Chapter 7. Free product (good or service) innovations have policy implications related to how product producers and users interact.

Implicit in both the OECD and the IMF recommendations is that they are directed at a market economy. This opens a potentially important discussion about innovation in all economic sectors and how it relates, or does not relate, to a market economy. This is where international organisations, such as the International Statistical Institute (ISI), the UN Statistics Division (UNSD), the UNESCO Institute Statistics (UIS), the IMF, the OECD, the World Bank and the World Intellectual Property Organization (WIPO), as well as the EU, a supranational organisation, could help set standards to guide digital economy statistical activities from which inferences could be drawn on innovation activities in the digital economy. Given the rate at which the digital economy is growing, the need for such a consensus is urgent if the innovation in the economy is to be understood.

Paunov and Planes-Satorra (2019: 32) explore how digital technologies are changing innovation in three industries in the business sector, agriculture, the automotive industry and retail. In the course of this study they raise a point about the role of $R \& D$ in innovation policy which also has measurement implications. The role of R\&D was discussed in Chapter 3 of this book where the point was made that more firms innovate than do $\mathrm{R} \& \mathrm{D}$ and that this is dependent on the (employment) size of the firm. The conclusion is that innovation statistics must go beyond R\&D.

In the case of the digital economy, Paunov and Planes-Satorra (2019) note that the following innovation activities might not be captured in R\&D investment statistics:

- data and software development innovation activities

- innovation in business processes

- business model innovation, and

- the role of capabilities for innovation. 
They observe that, as surveys are conducted at the firm level, they do not capture innovation activities lower down in the structure of the firm, at innovation project level, for example.

In their conclusion, Paunov and Planes-Satorra (2019: 39) note that there are five trends influencing the digital economy. They are that:

- innovation is increasingly data based, enabled also by the deployment of the Internet of Things

- services are at the centre of innovation

- innovation cycles are accelerating

- innovation processes are more collaborative and

- firms invest in new organisational capabilities to better embrace digital innovation.

These trends raise some important questions. The use of data and technologies, where data is functioning as technology, suggest that official statistics should include data on use and planned use of technologies in the digital economy. Recall the discussion of this in Chapter 8, Section 8.4 , and the role of user innovation. Services have dominated economies in most countries in the world for at least half a century and it is not a surprise that they play a key role in the digital economy in a world that is dematerialising. The acceleration of innovation cycles make time a key variable in understanding the digital economy and related innovation. Innovation processes are more collaborative in the digital economy, which reflects the complexity of the innovation activities and the need to involve different skills to deliver the innovation. Finally, investing in organisational capabilities is easier than reorganising a manufacturing plant.

With the digital economy, all sectors will be using, or trying to use, digital technologies and they will communicate with one another. To understand innovation in the digital economy, a systems approach is essential.

\subsection{SYSTEMS APPROACH}

The systems approach to measuring innovation was introduced in Chapter 2 as a means of classifying institutional units in all sectors and their interactions, and the role of framework conditions in promoting or impeding innovation in the institutional units. The general definition of innovation 
in Chapter 6 made it possible to use a standard measure of innovation and support comparisons with innovation activity in all sectors.

The next challenge is to build on previous measurement work to develop guidelines for the measurement of innovation in all economic sectors, using the general definition and the knowledge of measurement developed by researchers on public sector innovation and household sector innovation. Both domains have a long history of measurement but there is no equivalent to the Oslo Manual for the general government (public) sector, the NPISH sector or the household sector. Developing these manuals is the first challenge which will take years. The next challenge is to agree on ways of studying the entire innovation system in order to support the development of more effective innovation policy.

\subsection{INNOVATION AND POLICY}

Innovation policy leading up to the 2020s was discussed in Part II. Chapter 3 reflected the thinking in the recent past about how to promote innovation in the business sector and how the National Innovation Systems approach, and holistic innovation policy, were used to support innovation and to understand it. Chapter 4 provided an overview of how innovation policy, once implemented, could be monitored to demonstrate that it was achieving the desired objectives, or not. Chapter 5 then reviewed how innovation policy was developed in countries and internationally. Also introduced was the concept of 'restricted' innovation which was a means to observe broader policy objectives than just the propensity of an institutional unit (a firm in Part II) to innovate. Restrictions revealed innovation that supported green growth, inclusion, sustainability or other domains of policy interest.

Part III moved the domain of innovation from the business sector to all economic sectors. This was done by applying the general definition of innovation provided in the fourth edition of the Oslo Manual (OECD/ Eurostat 2018) and then using the economic sectors in the System of National Accounts (EC et al. 2009) as the domains for sector-specific measurement and analysis, going beyond innovation only in the business sector. However not all innovation is sector specific. Innovation in the informal economy is one example of a type of innovation happening in any or all economic sectors. It requires a different approach.

Moving from innovation in the business sector to innovation in any economic sector is a big step for both measurement and policy development. In parallel with broadening the domain of innovation policy, 
the digital economy is growing and is changing the way things are done and how innovation happens. In addition, with innovation happening everywhere, and differently, the links between actors in the same sector and with actors in other sectors are more important than they have been. The links can be feedback loops in an innovation system, and they can also be value chains, local or global, including skilled people, data, finance, knowledge, material or technologies. A key consideration is that the measurement and the analysis of linkages of all kinds could result in a deeper understanding of innovation than is available from a business sector perspective, leading to more effective policy interventions.

This discussion of innovation policy in the 2020s, and beyond, starts with the digital economy, then looks at the role of networks in policy development where the networks are made up of the linkages in the innovation system, connecting actors to one another and to framework conditions. This leads to a discussion of how innovation policy and its implementation are to be studied. This is an important issue now that innovation policy has the potential to be more insightful as well as being more complex than when it was directed at a single economic sector.

\subsection{DIGITAL ECONOMY AND INNOVATION POLICY}

As can be inferred from Paunov and Planes-Satorra (2019), when dealing with digital products and processes, innovation can be more sector specific than dealing with non-digital products and processes (a 'sector' here is a subset of the SNA business sector, such as manufacturing). In Chapter 6, an additional characteristic was discussed as a condition of innovation, the link between the producer and the user that provides the producer with a source of information about what the user is doing with the product. While this linkage is well established, there are unresolved questions about ethics and how the information is used.

The digital products that are provided at prices that are not economically significant, including zero, are raising questions about measurement and how the results fit into official statistics, such as the GDP. In Section 10.3, four actions were presented from OECD (2019a:17) as part of the measurement discussion. These actions also have implications for innovation policy in the digital economy as do the five specific actions in Section 10.3. 


\subsection{NETWORKS AND INNOVATION POLICY}

Chapter 2 described an innovation system that started with actors, the linkages between actors and the outcomes. The system was bounded by framework conditions which could prevent (trade barriers) or encourage (broadband access in all parts of the country) innovation. Measuring innovation in the business sector was a challenge and the measurement of innovation in all economic sectors will be more of a challenge. An important focus will be on linkages of which value chains are examples.

In the digital economy, more attention has to be given to digital platforms and the trust needed to support exchanges in the platform. Such platforms can be created and managed by institutional units in any economic sector and the exchanges made possible on the platforms can be between units in any economic sector. The platforms change with demand and participants. Industry 4.0 is an example that has been reviewed by Horst and Santiago (2018). They also comment upon platforms in developing countries.

\subsection{UNDERSTANDING INNOVATION POLICY AND ACTING ON IT}

In Chapters 3 and 5, there was discussion of the difficulties of understanding innovation policy and the learning which should result from monitoring and evaluation of implemented policy. These difficulties are not going to be simpler when the policy is expected to deal with more than one economic sector.

The chapters in PART III have demonstrated that innovation is global, complex, dynamic and non-linear in response to policy interventions. Using the systems approach discussed in Chapter 2, policy intervention may or may not result in the intended change as it can be influenced by other policy interventions and connections of the actors in the system with other actors. These connections may include local and global value chains.

Connection to other policy interventions is noted in the EU innovation policy fact sheet of the European Parliament. The description of innovation policy in the fact sheet is that:

It is also strongly linked to other EU policies, such as those on employment, competitiveness, environment, industry and energy. The role of innovation is to turn research results into new and better services and products in order to 
remain competitive in the global marketplace and improve the quality of life of Europe's citizens.

This makes the point that innovation does not happen in isolation and it can be influenced by other policy initiatives, deliberately or not.

Part of the Marburger objective, discussed in Chapter 3, remains, and it is the opinion that the policy process 'would be easier if we had "big models" of the sort economists use to intimidate their adversaries' (Marburger 2007: 30). Further discussion at the OECD Blue Sky Forum in 2006 (Gault 2013: 453) suggested that the minister of research/education/technology/innovation should receive advice comparable to that received by the equivalent of the minister of finance/economy, based on complex and intimidating models such as those used by economists. Finance ministries do indeed use big models of the economy to guide their interventions. At a time when products are being based on data, and there is powerful computing capacity available, there is an opportunity to model the effects of innovation in all economic sectors and how innovation in one sector can influence economic and social activities in other sectors.

Alessandra Colecchia (2007: 297), in summing up the 2006 OECD Blue Sky Forum II, shifted the emphasis of the Marburger proposal from the Ministry of Science and Technology, or of Industry, to the Ministry of Finance, as that was where the money was. Her goal was 'to ensure that the Ministers of Finance, and of the Economy, recognise STI policies as central to the promotion of economic growth and sustainable development'. We are not quite there yet, but the goal remains, as does the need for 'complex and intimidating models'.

\subsection{CONCLUSION}

The theme throughout this chapter is urgency, economic activity is changing and changing rapidly. Standard industrial classifications may need revision, the digital economy is changing the way innovation happens, and understanding innovation requires data gathering in all economic sectors of the SNA, noting that the means of gathering data is also changing. The suggestion is that internationally agreed manuals be produced to guide the measurement of innovation in all sectors but the business sector, which already has the Oslo Manual (OECD/Eurostat 2018), now in its fourth edition. This provides an opportunity for different organisations with subject matter knowledge, and different parts of 
organisations, to collaborate on providing guidelines for the measurement of innovation in the sector for which they are responsible.

Possible organisations are the ISI and its sub-organisations, the ISO, the International Telecommunication Union (ITU) and the WIPO. Other organisations could be considered.

\section{NOTES}

1. There are other means of collecting data discussed in the two US papers, National Research Council (2014) and National Academies of Sciences, Engineering and Medicine (2017).

https://unstats.un.org/wiesbadengroup/ (accessed 17 March 2020).

1. Countries may have their own standard industrial classification, and there are classifications covering more than one county. North America, Canada, Mexico and the US have the North American Industry Classification System (NAICS) (Executive Office of the President 2017). The EU has the Nomenclature des Activités Économiques dans la Communauté Européenne (NACE), now in its second revision (Eurostat 2008).

4 To see the OECD Digital Economy Papers and Country Studies, go to http:// www.oecd-ilibrary.org (accessed 17 March 2020) and search on 'digital'.

5. The role of value chains in systems of innovation has taken some time to enter the innovation systems discussion. The reader is encouraged to look at 'Global value chains meeting innovation systems: Are there learning opportunities for developing countries' (Pietrobelli and Rabellotti 2011).

6. See http://www.europarl.europa.eu/factsheets/en/sheet/67/innovation -policy (accessed 17 March 2020).

7. The author has observed a country which stopped a major research facility for sound reasons, viewed from one policy perspective, but which was at variance with the policy objective of another government department which was to raise the level of R\&D performance in the country. Policy coherence remains a challenge. 